\title{
Bubble Evolution on Different Carbon Anode Designs in Cryolite Melt
}

\author{
NIKOLINA STANIC, IVANA JEVREMOVIC, ANA MARIA MARTINEZ, \\ and ESPEN SANDNES
}

The anode potential has been shown to be highly dependent on anode geometry and orientation in the Hall-Héroult process. This work is an experimental laboratory scale study of the effect of anode geometry and orientation on bubble formation and detachment for four different anode designs: horizontal (surface facing downwards), inverted horizontal (surface facing upwards), vertical, rod (with both vertical and horizontal surface). From polarization curves, it was found that the vertical anode and the inverted horizontal anode operated at lowest potentials. Above 1 $\mathrm{A} \mathrm{cm}{ }^{-2}$, the vertical anode showed the lowest potential. As the current increases, the transition towards smaller noise is pronounced for the horizontal anode and to some degree for the vertical anode and inverted horizontal anode. Fast Fourier Transform analysis of chronoamperometric data gave a dominant frequency only for the horizontal anode and the rod anode. The bubble release time corresponded well with the dominant frequency for the rod anode for all current densities and for the horizontal anode at lower current densities. Only random bubble noise was found for the vertical and the inverted horizontal anode and is probably due to a bubble-induced convection effectively removing the bubbles.

https://doi.org/10.1007/s11663-020-01835-7

(C) The Author(s) 2020

\section{INTRODUCTION}

THE anode reaction in the Hall-Héroult process is complicated because it involves discharge of oxide present in oxyfluoride complex ions, among others $\mathrm{Al}_{2} \mathrm{OF}_{6}^{2-}$ and $\mathrm{Al}_{2} \mathrm{O}_{2} \mathrm{~F}_{4}^{2-}$, presumably adsorption of oxygen at the carbon anode and a following thermal or electrochemical desorption. ${ }^{[1,2]}$ The electrolysis takes place in cryolite melt $\left(3 \mathrm{NaF}-\mathrm{AlF}_{3}\right)$ with dissolved alumina but discharge of fluoride ions does not take place during normal electrolysis since this potential is higher than the discharge potential of the oxyfluoride complexes. The overall reaction can be one or both of the following:
NIKOLINA STANIC, IVANA JEVREMOVIC, and ESPEN SANDNES are with the Norwegian University of Science and Technology, 7491 Trondheim, Norway. Contact e-mail: nikolina.stanic@ntnu.no ANA MARIA MARTINEZ is with the SINTEF Industry, 7034 Trondheim, Norway.

Manuscript submitted June 20, 2019.

Article published online April 14, 2020.

$$
\begin{gathered}
2 \mathrm{Al}_{2} \mathrm{O}_{3}(\mathrm{l})+3 \mathrm{C}(\mathrm{s}) \rightarrow 4 \mathrm{Al}(\mathrm{l})+3 \mathrm{CO}_{2}(\mathrm{~g}) \\
E^{0}=-1.16 \mathrm{~V} \\
\mathrm{Al}_{2} \mathrm{O}_{3}(\mathrm{l})+3 \mathrm{C} \rightarrow 2 \mathrm{Al}(\mathrm{l})+3 \mathrm{CO}(\mathrm{g}) E^{0}=-1.02 \mathrm{~V}
\end{gathered}
$$

The cathode product is liquid aluminum, and the anode product is a $\mathrm{CO}_{2} / \mathrm{CO}$ gas mixture. As a result, carbon anodes are consumed. The main primary anode product is $\mathrm{CO}_{2}(\mathrm{~g})$, but some $\mathrm{CO}$ can be formed at low current densities $0.05-0.1 \mathrm{~A} \mathrm{~cm}^{-2}$. 3$]$

Several mechanisms are proposed for the anode reaction. Picard et al. ${ }^{[4]}$ studied reaction [1] using electrochemical impedance and proposed the following three-step mechanism at low current densities and low overpotentials:

1. Diffusion of the oxyfluoroaluminate species from the bulk of the melt to the surface of the graphite anode:

$$
\mathrm{AlOF}_{x}^{1-x} \text { (melt) } \rightarrow \mathrm{AlOF}_{x}^{1-x} \text { (electrode) }
$$

2. Dissociation of the oxyfluoroaluminate species and adsorption of the oxide ions, followed by their discharge and the formation of the adsorbed carbon-oxygen species:

$$
\mathrm{AlOF}_{x}^{1-x}+\mathrm{C} \rightarrow \mathrm{CO}_{\mathrm{ads}}+\mathrm{AlF}_{x}^{3-x}+2 e^{-}
$$


3. Dissociation of the oxyfluoroaluminate species and the adsorption of the oxide ions, their discharge in the presence of the $\mathrm{CO}_{\mathrm{ads}}$ and the formation of the gaseous $\mathrm{CO}_{2}$ :

$$
\mathrm{AlFO}_{x}^{1-x}+\mathrm{CO}_{\mathrm{ads}} \rightarrow \mathrm{CO}_{2}(\mathrm{~g})+\mathrm{AlF}_{x}^{3-x}+2 e^{-}
$$

A similar mechanism with the electrochemical desorption step was also proposed by Kisza et al. ${ }^{[5]}$ Thonstad $^{[3]}$ also proposed an electrochemical adsorption followed by a thermal desorption step involving a combination of two $\mathrm{CO}_{\text {ads }}$ species.

The most important reaction responsible for the loss in current efficiency in the aluminum electrolysis is the back reaction between dissolved $\mathrm{CO}_{2}$ and dissolved $\mathrm{Al}$ and $\mathrm{Na}$ in the melt. The sodium is created through the reaction between aluminum and sodium fluoride at cathode/electrolyte interface. The back reaction can be written $^{[6,7]}$ :

$$
2 \mathrm{Al} \text { (diss.) }+3 \mathrm{CO}_{2} \text { (diss.) } \rightarrow \mathrm{Al}_{2} \mathrm{O}_{3} \text { (diss.) }+3 \mathrm{CO}(\mathrm{g})
$$

The CO content in the anode off-gas can arise from the electrochemical reaction directly, from the back reaction and also from the Boudouard reaction:

$$
\mathrm{CO}_{2}+\mathrm{C} \rightarrow 2 \mathrm{CO}
$$

The carbon can come from the anode itself or carbon dust in the melt. At 950 to $1000{ }^{\circ} \mathrm{C}$, the equilibrium is displaced far to the right.

Spherical gas bubbles have been found in laboratory experiments to initially be generated on the downward-facing anode surface and released in a cyclic pattern. ${ }^{[8]}$ Zhao et al ${ }^{[9]}$ studied anodic bubble behavior in a laboratory scale transparent aluminum electrolysis cell using a cylindrical anode shielded by an alumina tube giving only a horizontal downward-facing active area. Individual bubbles were observed which grew to a certain size and coalesced to form larger bubbles. The bubbles expanded and almost covered the full bottom surface. The bubbles then slided towards the edge of the anode and were released from the anode bottom. Cassayre et al..$^{[10]}$ also studied bubble formation in a transparent cell and found that periodic gas bubble release occurred. Bubble nucleation occured at specific spots. On the downward-facing horizontal part of the anode, bubbles come into contact with each other and coalesce first into large individual bubbles and then further coalesce into a single bubble covering a bigger area. When the bubble layer reaches the anode edge, the gas bubble rises rapidly because of buoyancy. Bubble coalescence was also observed on vertical anode surface.

Gas present at the anode surface contributes to an increase cell voltage as the current lines between the anode and cathode become prolonged. This is also in the literature referred to as a bubble overvoltage. In addition, charge transfer and concentration overvoltage contribute to total cell voltage. The bubbles can be responsible for as much as 10 pct of the total cell voltage, which gives a significant contribution to the energy consumption. ${ }^{[11]}$ Reducing energy consumption in aluminum electrolysis is of major importance for production cost savings and for reduction of greenhouse gas emissions.

Hyperpolarization is by definition a voltage component at gas evolving electrodes due to the masking of the electrode by bubbles, i.e., active surface area is reduced by a bubble covering part of the electrode surface. This causes areas with higher local current density than the calculated current density based on the geometric area. The increased current density causes increased charge transfer overvoltage. Hyperpolarization causes increase in concentration overvoltage. ${ }^{[12]}$ The extra voltage drop due to bubbles is about 0.15 to $0.35 \mathrm{~V}$ out of a typical total cell voltage of $\sim 4.5 \mathrm{~V} .{ }^{[9]}$ The additional voltage increase due to bubbles has been shown to be highly dependent on anode geometry and orientation.

The aim of the present work was to study bubble behavior of different laboratory scale anode designs. The anodes used in this paper are typically used to study reaction kinetics and mass transport, anode effect phenomena, current efficiency, anode quality properties, etc. It is therefore interesting to study bubble dynamics of these anodes in more detail because bubble dynamics are relevant for all the above-mentioned features. Four anode designs were made: horizontal anode (with a downward-facing surface), vertical anode, rod anode (having both a vertical and horizontal surface), and inverted horizontal anode (with an upward-facing surface). The first three anode designs have been reported in earlier papers. ${ }^{[12,13]}$ The inverted horizontal anode, not previously reported, was constructed to have a horizontal surface which has faster bubble release in comparison to a downward-facing horizontal anode where bubbles can not be released easily due to the buoyancy alone. The measurements included bubble-induced current and potential oscillations.

\section{EXPERIMENTAL}

Four electrode designs were used to investigate the impact of electrode geometry and orientation on anode reaction in aluminum electrolysis. The electrodes were constructed as shown in Figure 1. As a counter electrode was used a graphite rod shielded with the boron nitride which gave a surface area of $10.2 \mathrm{~cm}^{2}$. The carbon crucible could have been used as a counter electrode but the shielded rod design was needed for later gas measurements in the same experimental setup. Risking to have an uneven current distribution on the anode the bubble behavior and polarization curves of the horizontal and the vertical anodes were compared with the work of Thorne et al. ${ }^{[12,13]}$ The comparison showed very similar bubble behavior and potential-current values for the polarization curves. It was therefore concluded that the chosen electrode configuration could be used. A purified graphite material (Schunk Tokai Scandinavia $\mathrm{AB}$, Sweden) was the active electrode material. Figure 1(a) shows the horizontal anode design. A graphite rod and a stainless steel rod were threaded together and 


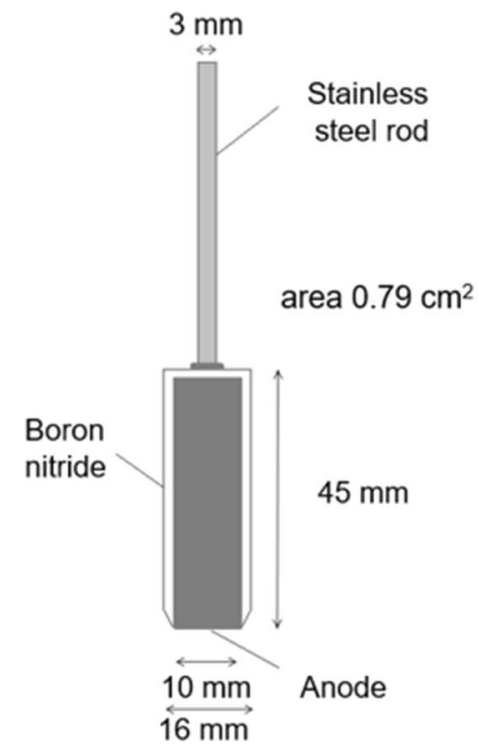

(a)

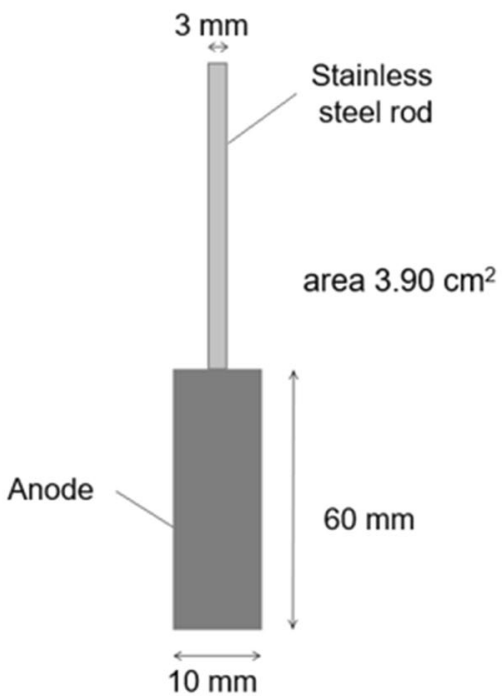

(c)

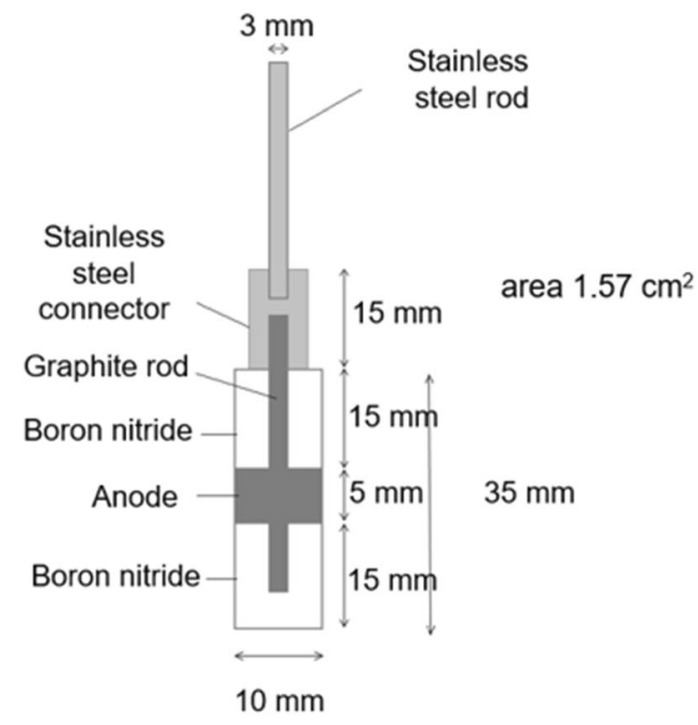

(b)

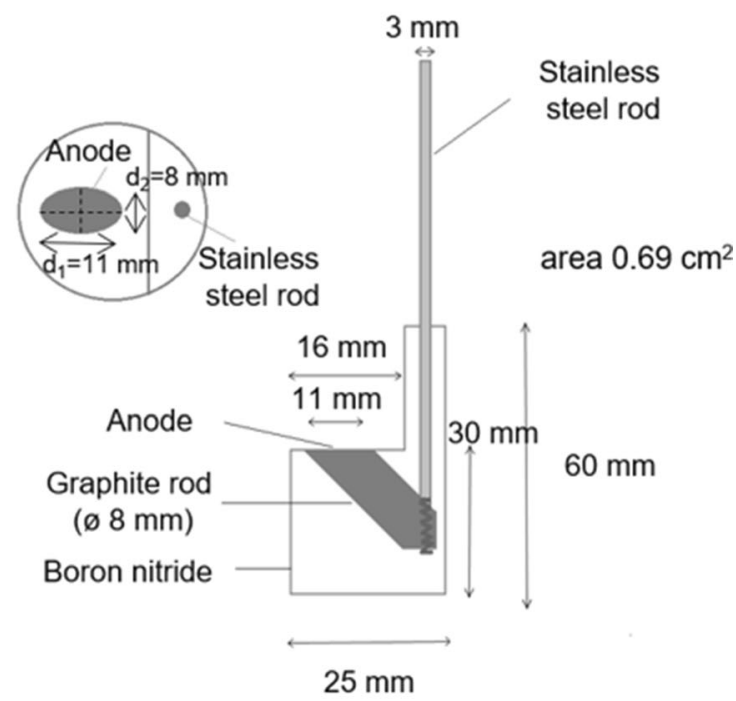

(d)

Fig. 1-Different anode designs: $(a)$ horizontal anode, $(b)$ rod anode, $(c)$ vertical anode, $(d)$ inverted horizontal anode (inset shows electrode seen from above).

the sides of the graphite were shielded using boron nitride to expose only the horizontal surface when anode is immersed in the melt. The horizontal anode was made as described in Reference ${ }^{[12]}$ with the differences that boron nitride edges were cut off by an angle of 45 degrees to provide easier bubble detachment. The rod anode in Figure 1(b) has mixed geometry, i.e., horizontal and vertical surfaces. The rod anode was made as described in Reference ${ }^{[14]}$. The anode was immersed 10 $\mathrm{mm}$ in the melt, which gave it a geometric surface area of approx. $3.9 \mathrm{~cm}^{2}$. The vertical anode design in Figure 1(c) had a defined surface area by using boron nitride shielding and it was made as described in Reference ${ }^{[13]}$. The inverted horizontal design in Figure 1(d) is an anode design that has not been previously reported. Holes for the graphite and the stainless steel rod were drilled in the boron nitride. Electrical contact between graphite and stainless steel was obtained by making threaded connection. The electrical contact was further improved by adding graphite dust in the threads. A horizontal cut of the graphite rod was made which gave the anode surface area the shape of a horizontal ellipse with an area of $0.69 \mathrm{~cm}^{2}$.

There are large differences in the area between the anode designs. However, more important for comparison of bubble behavior of each anode design is the dimensional length of the electrode, e.g., the diameter of the horizontal anode and rod anode was $10 \mathrm{~mm}$, the immersion depth of the rod was $10 \mathrm{~mm}$, and the diameters for the inverted horizontal anode were $\mathrm{d}_{1}=$ $11 \mathrm{~mm}$ and $\mathrm{d}_{2}=8 \mathrm{~mm}$. The height for the vertical anode was only $5 \mathrm{~mm}$ but still considered to be 
comparable to the other anodes as the bubbles on the vertical surface have been reported to be relatively small and this design was earlier successfully used. ${ }^{[1,15]}$ Experiments were performed under inert $\mathrm{N}_{2}$ atmosphere in a cryolite melt. The cryolite was supplied from Sigma Aldrich (purity $\geq 97$ pct, cryolite ratio $=3$ ). The alumina concentration was 2 wt pet (Merck). The temperature was $1005^{\circ} \mathrm{C}$. The melt was contained in a graphite crucible (Schunk Tokai Scandinavia AB, Sweden). The aluminum reference electrode was fabricated according to Reference ${ }^{[16]}$. The schematic setup of the cell is shown in Figure 2.

Electrochemical Impedance Spectroscopy (EIS) was used to determine the ohmic resistance at Open Circuit Potential (OCP). This value was used to IR compensate all electrochemical measurements. This means that any voltage drop due to resistance introduced by bubbles and overvoltage has not been compensated. This partial IR compensation is deliberate because the intention was to study the effect of anode design on bubbles. The potential of the working electrode (anode) was measured with respect to an aluminum reference electrode. Linear Sweep Voltammetry (LSV) was performed sweeping from OCP and up to $2.6 \mathrm{~V}$ at a sweep rate of $5 \mathrm{mV} \mathrm{s}^{-1}$. The effect of anode geometry on bubble behavior was also studied by using chronopotentiometric measurements with current densities in the range 0.1 to $1.0 \mathrm{~A}$ $\mathrm{cm}^{-2}$. Potential vs time measurements were transformed into frequency spectra by using a Fast Fourier Transform algorithm in Matlab. The signals were transformed into the frequency domain to evaluate how the power of the signal is distributed over a range of frequencies. The frequency spectrum is a simple way of showing the total amplitude at each frequency. The highest frequency that can be represented is one-half the sampling frequency, called the Nyquist frequency. The sampling rate (Fs) was $5 \mathrm{~Hz}$ when applied current density was lower than $0.5 \mathrm{~A} \mathrm{~cm}^{-2}$, and $10 \mathrm{~Hz}$ for applied current density $>0.5$ A $\mathrm{cm}^{-2}$, consequently the spectrum has a frequency

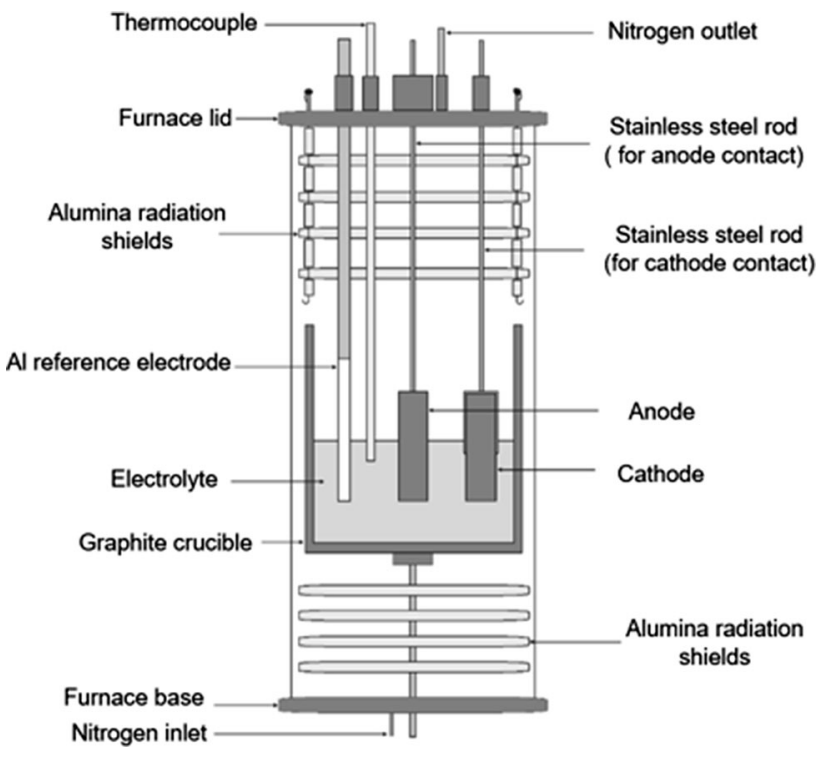

Fig. 2-The cell setup. range from zero to $\mathrm{Fs} / 2,0$ to $2.5 \mathrm{~Hz}$ and 0 to $5 \mathrm{~Hz}$, respectively. Dominant frequency is considered the frequency where FFT peak with the maximum magnitude of the signal is observed. All electrochemical measurements were carried out using a PARSTAT (Princeton Applied Research) potentiostat and a $20 \mathrm{~A}$ booster (KEPCO).

\section{RESULTS AND DISCUSSION}

In Figure 3, polarization curves for different anode designs are presented. The polarization curves are actually obtained by using the LSV method. It was checked that a sweep rate of $5 \mathrm{mV} \mathrm{s}^{-1}$ was sufficiently low to permit steady state, meaning the voltammogram followed the same E-I relation as a stationary polarization curve, except the bubble noise visible in the voltammogram. Thorne et al. ${ }^{[13]}$ presented voltammograms which were recorded at even higher sweep rate, $100 \mathrm{mV} \mathrm{s}^{-1}$, and claimed these curves to also give steady state. Starting from OCP, the first increase in current in Figure 3 is observed at $1.4 \mathrm{~V}$ for all anode designs. The current increase was due to $\mathrm{CO}_{2} / \mathrm{CO}$ gas evolution. ${ }^{[14]}$ After initiation of gas evolution, the current for the different anode designs started to differ. The curves in Figure 3 all show varying degree of current oscillations. These oscillations arise from growth, coalescence and detachment of bubbles and are also referred to as bubble noise. The polarization curve for the horizontal anode is shown separately in Figure 3(b). Due to the large amount of bubble noise for this anode, the polarization curve shown in Figure 3(a) has been smoothed for easier comparison. Bubble behavior is influenced by wetting of the anode by the melt. Good wetting (i.e., small wetting angle) implies low coverage and easier movement of the bubbles on the anode surface. The wetting angle is decreasing with increasing polarization/current density until anode effect occurs and varies in level somehow with the carbon anode material. ${ }^{[1]}$ Since the same graphite material is used for all anodes in the present work, it is assumed that comparison of the anode performance at similar potential/current density values is meaningful.

The current oscillation for the horizontal anode is the largest among the anodes, while the current oscillation for the vertical anode is the smallest. Figure 4 shows current oscillations for the polarization curves in Figure 3 normalized around the smoothed average for easier comparison of the noise. At lower potentials, the current density of the horizontal anode is low, meaning the bubbles are forming slowly. As the bubble detaches, there is a sudden increase in the current. This periodic behavior causes the characteristic saw-tooth shape of the polarization curve. The saw-tooth shape is visible up to $2.1 \mathrm{~V}$. Above $2.3 \mathrm{~V}$, more stochastic behavior is pronounced rather than periodic indicating nucleation and growth on more sites. Between $2.1 \mathrm{~V}$ and $2.3 \mathrm{~V}$, a transition from periodic behavior to stochastic behavior occurs. This transition is caused by bubble-induced convection promoting easier bubble release resulting in a decrease in the bubble noise. In the same potential 


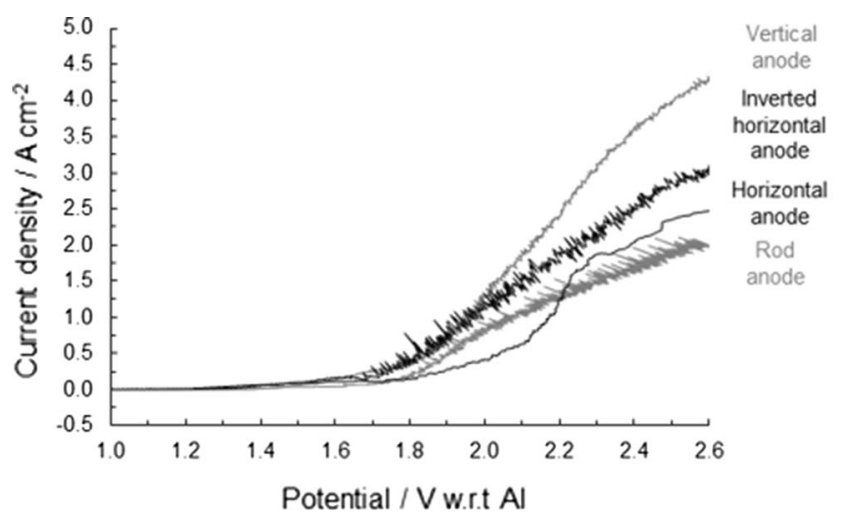

(a)

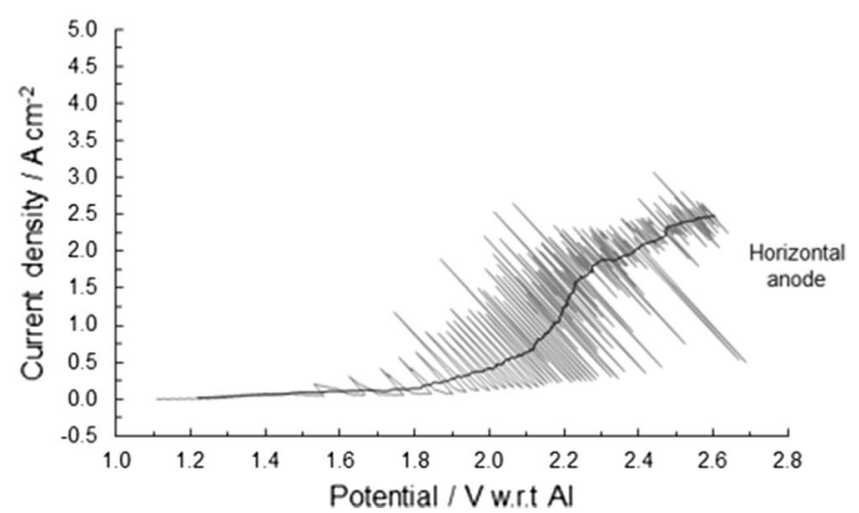

(b)

Fig. 3-Polarization curves for rod, vertical, inverted horizontal, and horizontal anode. Polarization curves are IR-compensated with the value of ohmic resistance at OCP. (a) All anode designs plotted together for comparison. The polarization curve of the horizontal anode is smoothed using the moving average method (100 points) for easier comparison. (b) Actual polarization curve together with the smoothed curve.

range, it is also observed a faster increase in current. This improvement in the performance of the horizontal anode is also linked to the improved bubble-induced convection.

The polarization curve of the vertical anode (Figures 3 and 4) shows a similar noise trend compared to the horizontal polarization curve, meaning there is an increase in the noise up to around $2.1 \mathrm{~V}$ followed by a small decrease in the noise. The bubble noise is significantly smaller than for the horizontal anode. This could be due to the evolution of smaller bubbles from the vertical surface, caused both by the buoyancy force making a detachment easier as well as the induced convection regime being more efficient for bubble detachment compared to the horizontal anode.

The mixed geometry of the rod anode suggests the polarization curve to follow the same noise trend as the combination of the horizontal and the vertical anode. However, the polarization curve gets noisier with increasing potential without going through a transition towards smaller noise. The polarization curve in Figure 3 shows that at similar potential the current density is 2 to 3 times higher for the vertical than for the horizontal anode. This indicates that the current density of the vertical part and the horizontal part of the rod anode has a similar relation. The rod was immersed 10 $\mathrm{mm}$ giving a ratio between the vertical and the horizontal area of the rod of approx. 4. There is an uncertainty regarding current density of the rod anode arising from the uncertainty in immersion depth of the rod. However, within reasonable error, the major fraction of the current is taken up by the vertical surface. This should make the bubble noise of the rod anode to more resemble the noise of the vertical anode than the horizontal anode. However, at the same time, the bubble noise contribution from the horizontal part is expected to be large based on the noise seen for the horizontal anode. The bubble noise for the rod anode is slightly larger compared to the vertical and considerably smaller compared to the horizontal anode. The clear transition seen for the horizontal anode is not observed for the rod anode as the current density of the horizontal part of the rod anode never reaches a current density as high as the current density for where the transition for the horizontal anode was observed. It was unexpected that the rod anode operated at the higher potentials than the horizontal anode as most of the current is taken up by the vertical part. As the rod anode is positioned at the melt surface, the bubble-induced convection at higher current density is less efficient since bubbles escape the electrode at the melt surface into the furnace atmosphere. This escape does not contribute to any bubble-induced convection. Thonstad reported critical current densities on graphite anodes for different alumina concentrations. ${ }^{[18]}$ Comparing the current densities obtained in the present work with Thonstad's work, it seems that the current densities for all anodes are approaching the limiting current densities at the highest potential. The flattening out of all polarization curves at the highest potentials is caused by increased reaction overpotential in generals and increased gas coverage with hyperpolarization as a consequence. On the other hand, the better gas bubble-induced convection is diminishing this effect by more effective transport of reactants towards the surface and reduced Nernst diffusion layer.

The polarization curve for the inverted horizontal anode has a high noise already from lower potentials (Figures 3 and 4). The noise stays practically unchanged up to $2.3 \mathrm{~V}$ where it decreases slightly, but the transition to lower noise seen for the horizontal anode and the vertical anode is much less pronounced. The bubble noise is slightly larger than for the vertical anode. The current density at higher potentials is lower than compared to the vertical anode. The difference in bubble noise and current density is related to the ability of these two anodes to create bubble-induced convection as discussed in relation to Figure 7.

Figure 5 represents potential-time characteristics of the different anode designs for constant geometric current densities. Potential oscillation is a function of applied current, the bubble size and the bubble coverage 

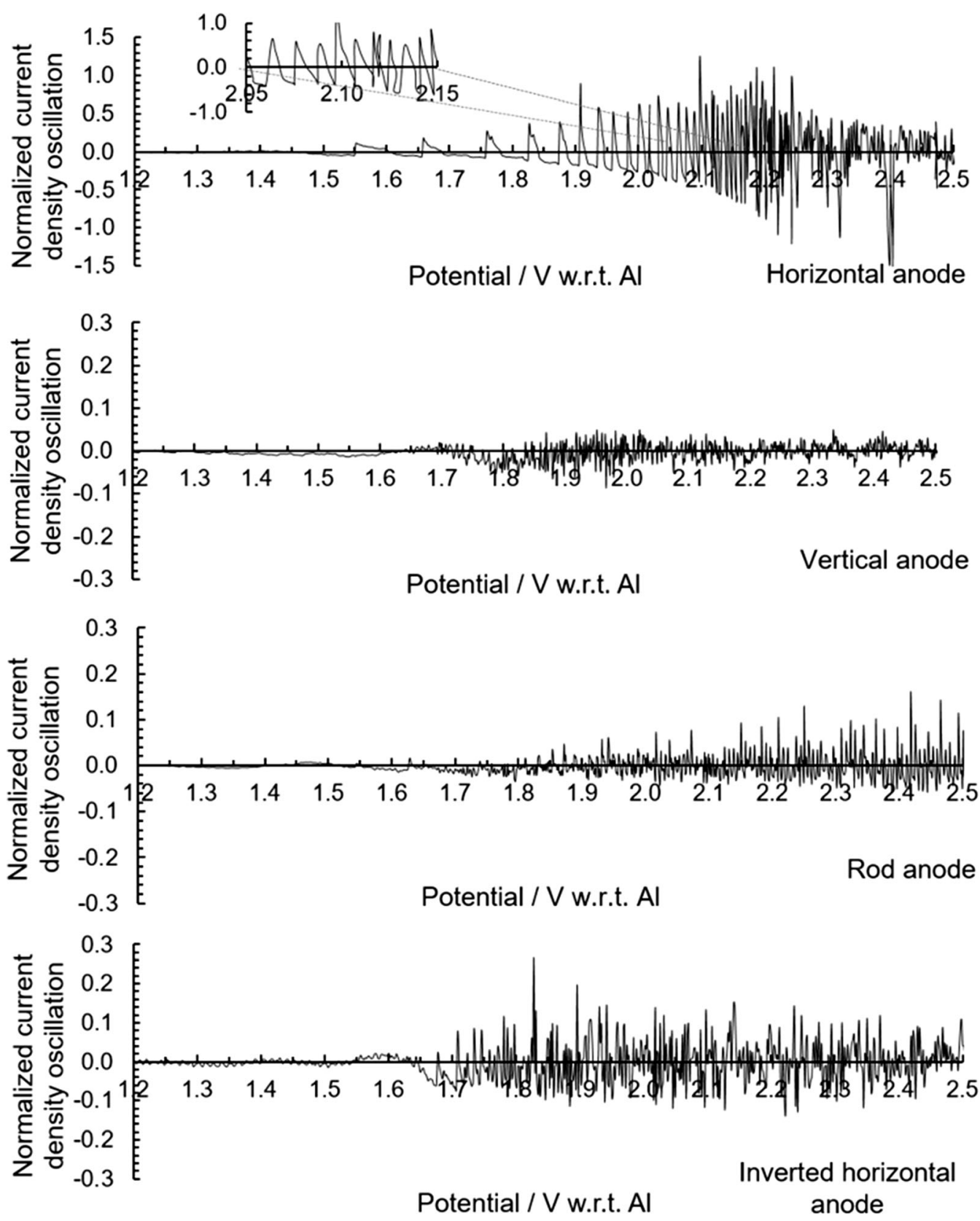

Fig. 4-Data of current density oscillation for rod, vertical and inverted horizontal and horizontal anode, normalized around smoothed average. Data are IR-compensated with the value of the ohmic resistance at OCP.

among others, all of which are interdependent. As a bubble grows, it covers more and more of the anode surface causing the potential to increase as the local current density increases. When the bubble detaches, the local current density decreases and consequently the potential decreases. ${ }^{[9]}$ Zhang et al. ${ }^{[20]}$ have combined use of physical and numerical modeling and have found that the bubble size influences the bubble-induced potential drop and local current distribution. The bubble-induced resistance increases as the bubble size increases. For large bubbles, the current needs to travel longer distance to bypass the bubbles leading to higher potential drop. In addition, hyperpolarization increases with increasing bubble surface coverage. As bubbles are formed, the potential increased due to combination of increase in ohmic resistance and hyperpolarization due to a decrease in effective surface area. ${ }^{[12]}$ The current oscillation for different anode designs has been qualitatively described in relation to the data in Figure 3. Much of the same reasoning can be applied to the potential-time characteristics shown in Figure 5.

Figure 6 shows the potential oscillations under galvanostatic control (at $0.5 \mathrm{~A} \mathrm{~cm}^{-2}$ ) for the horizontal anode. The figure is included to show the details of the characteristic saw-tooth curve. The bubble growth is characterized by an almost linear growth in potential and the sharp potential drop is due to bubble detachment. The linear growth is a superposition including 

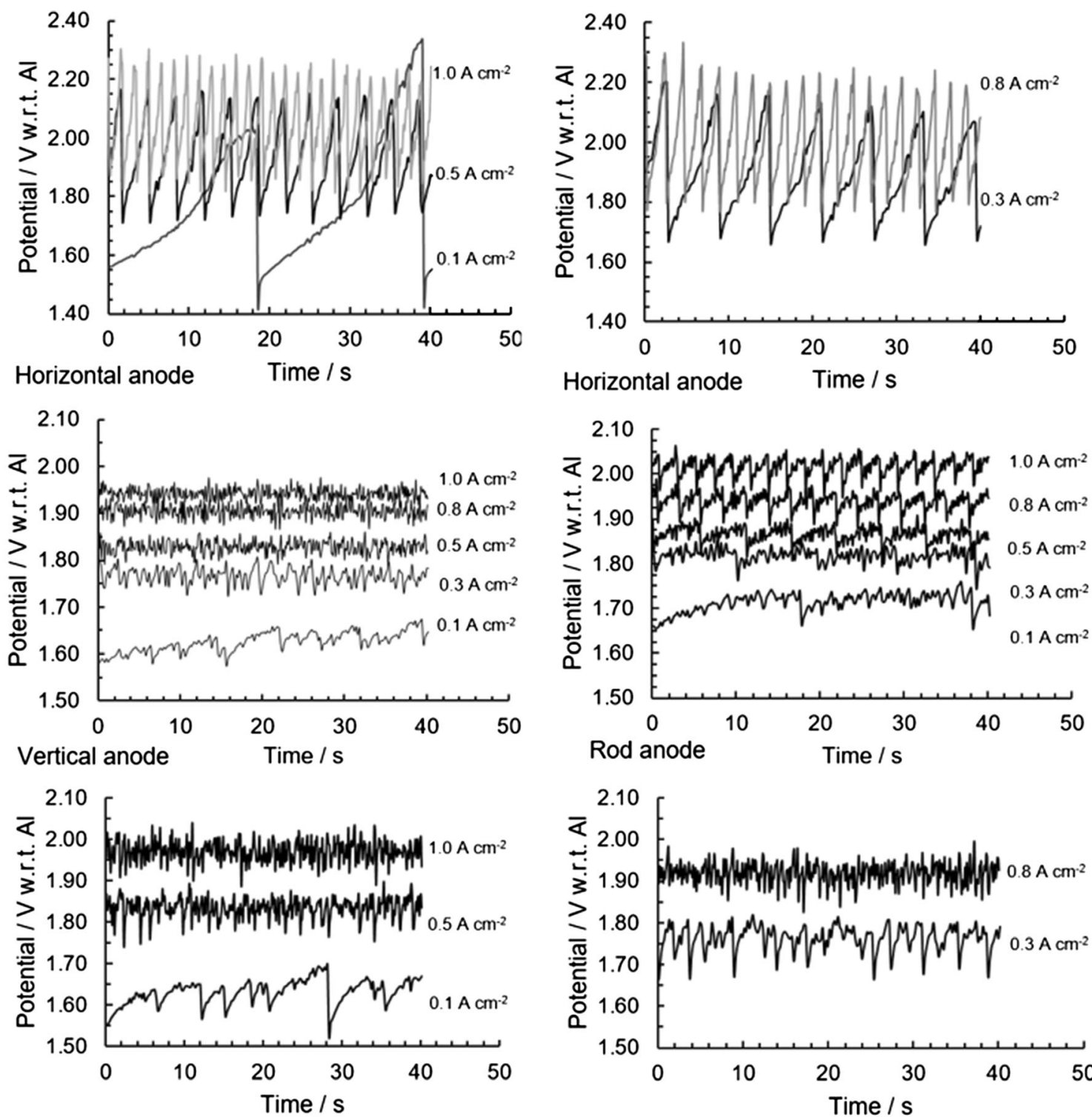

Inverted horizontal anode

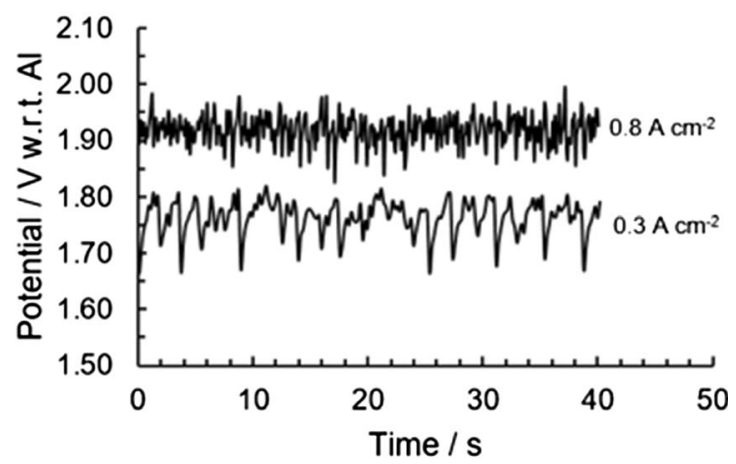

Inverted horizontal anode

Fig. 5-Measured anode potential vs time during electrolysis at different current densities.

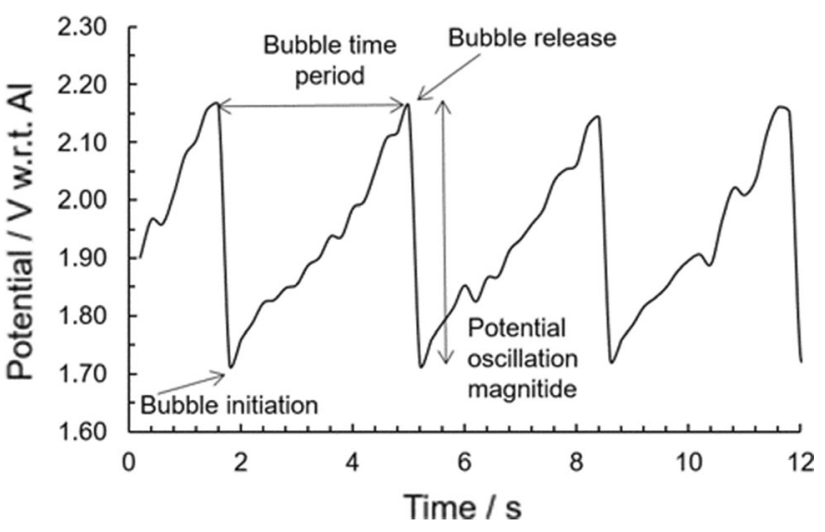

Fig. 6-Details of the saw-tooth-shaped potential vs time curve for the horizontal anode at $0.5 \mathrm{~A} \mathrm{~cm}^{-2}$. potential oscillations also from smaller bubbles being formed, coalesced or detached during the development of the larger bubble. Xue and Øye ${ }^{[21]}$ designed a transparent electrolysis cell to allow a single bubble to be formed underneath a horizontal anode and detached from the anode surface so that its life cycle could be observed. They concluded that the frequency with the largest amplitude is coupled with the detachment of the bubble. This process, i.e., bubble nucleation-growthdetachment, is pseudo-periodical. ${ }^{[21]}$

The saw-tooth shape of the potential oscillation is by far most pronounced for the horizontal anode which keeps this feature up to $1 \mathrm{~A} \mathrm{~cm}^{-2}$. The vertical anode shows stochastic and small potential oscillation without forming saw-tooth curve at higher current density, but at lower current densities $\left(0.1\right.$ and $\left.0.3 \mathrm{~A} \mathrm{~cm}^{-2}\right)$ saw-tooth features can be observed. The vertical anode has smallest bubble retention time in comparison to the 
horizontal anode. Thorne et al. reported similar trends. ${ }^{[14,15]}$ The inverted horizontal anode has similar behavior to the vertical anode at current densities $>0.5$ $\mathrm{A} \mathrm{cm} \mathrm{cm}^{-2}$, i.e., random potential oscillation, and at lower current densities $\left(0.1\right.$ to $0.3 \mathrm{~A} \mathrm{~cm}^{-2}$ for vertical and 0.1 to $0.5 \mathrm{~A} \mathrm{~cm}^{-2}$ for inverted horizontal anode) saw-tooth features are present. However, inverted horizontal anode has larger noise as discussed below. Cassayre et al. observed ${ }^{[10,22]}$ that at higher current densities coalescence takes place to a smaller degree than at low current densities and the bubbles escape before covering the whole anode. The same authors also found that with increasing current density smaller bubbles formed and detached more frequently. Zhao et al. ${ }^{[23]}$ studied anodic bubble behavior in a laboratory scale transparent aluminum electrolysis cell and found that faster gas generation rate at high current density causes more turbulence which may play significant role for the quick release of the bubbles from the surface. In the current work, the lack of bubble coalescence due to faster bubble detachment could explain disappearance of the saw-tooth-shaped potential oscillation for vertical and inverted horizontal anode with increasing current density. The presence of weak saw-tooth features for these anodes at low current densities can then be explained by bubble retention time large enough to allow some degree of coalescence and bubble growth. Saw-tooth features exist up to $0.5 \mathrm{~A} \mathrm{~cm}^{-2}$ for the inverted horizontal but not for the vertical anode. Anode geometry plays a role as it can be argued that bubbles are released more easily from a vertical than from a horizontal facing upward surface. In the case of the vertical anode, there is a replacement of the bubble volume by bath coming from the side and from below, illustrated in Figure 7(a). Zhang et al. ${ }^{[24]}$ established a Zn electrowinning model based on the Nernst-Plank equation and electrode gas evolution reaction kinetics. This model-calculated fluid flow field is comparable to the vertical anode in the present work. The model shows an upward fluid flow with the anode surface due to bubble-induced convection arising from formation of oxygen bubbles. The flow direction is parallel to the anode surface and a large vortex is formed at the upper part of the cell. As bubbles rise to higher position the flow velocity typically increases because of bubble coalescence approaching

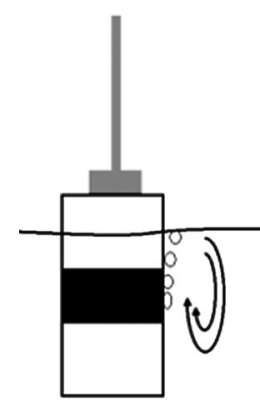

(a)

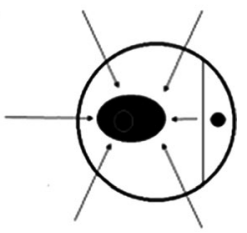

(b)
Fig. 7-Bubble-induced bath flow patterns close to electrode surface: (a) vertical design, (b) inverted horizontal design. the maximum value at the top of the cell. The anode height was $15.5 \mathrm{~cm}$. The $0.5 \mathrm{~cm}$ height of the vertical anode in the present work is small compared to Zhang et al. which indicates that difference in flow rate at the bottom and top of the vertical anode is insignificant. In the case of the inverted horizontal anode, the bath flow parallel to the surface is likely to be smaller than for the vertical anode as the bubble volume is replaced by bath coming from the whole periphery of the electrode causing a decrease in the flow as the center of the electrode is reached, illustrated in Figure 7(b). In addition, the flow lines will have a vertical component. The upward flow along the vertical anode makes bubble detachment efficient after a certain bubble production rate has been obtained. This effect seemed to be pronounced at current densities larger than $0.3 \mathrm{~A}$ $\mathrm{cm}^{-2}$ as seen in Figure 5.

The rod anode exhibited potential oscillation magnitude between the horizontal and the vertical anode, something also observed by Thorne et al. ${ }^{[12]}$ Xue and $\varnothing y e^{[21]}$ also applied a rod anode but with an immersion depth of only $1 \mathrm{~mm}$ compared to $10 \mathrm{~mm}$ in the present work. This gave a saw-tooth shape not as pronounced as the horizontal anode but certainly more pronounced than the rod anode. The relatively small noise of the rod anode suggests that the current density on the vertical part of the surface of the rod anode is higher than on the horizontal part of the surface.

Fast Fourier transform analysis (FFT) of the potential $v s$ time measurements for all anode design at different current densities is shown in Figure 8. A dominant FFT frequency was only observed for the horizontal and the rod anode, for the rod anode in the frequency range 0.05 to $0.5 \mathrm{~Hz}$ and for the horizontal anode in the frequency range 0.05 to $1.3 \mathrm{~Hz}$. This indicates a clear periodicity of the potential-time data in the case of the horizontal anode and the rod anode. The rod anode shows dominant frequencies due to the larger bubbles detaching from the horizontal part. The FFT dominant frequency corresponded well with bubble detachment time for the rod anode for all current densities (Table I). For the horizontal anode, the FFT dominant frequency corresponded well except at higher current densities, 0.8 and $1.0 \mathrm{~A} \mathrm{~cm}^{-2}$, i.e., the dominant frequency became higher than expected based on the bubble detachment time. Einarsrud et al. ${ }^{[25]}$ found a discrepancy between bubble detachment times and dominant FFT frequencies and attributed this to a lack of periodicity in the bubble noise signal, possibly due to overlapping bubbles. Looking at the potential-time curve for the horizontal anode (Figure 6), there is a small noise in the linear part of the saw-tooth curve which might be caused by coalescence and/or overlapping of the bubbles. Good correlation between FFT dominant frequency and bubble detachment time was also obtained by Thorne et al ${ }^{[12]}$ for a horizontal $8 \mathrm{~mm}$ diameter graphite anode. In the frequency spectrum for the vertical and inverted horizontal anode (Figure 8), there are several peaks, but none of them can be characterized as dominant. These peaks are related to smaller potential oscillations that can be due to the 


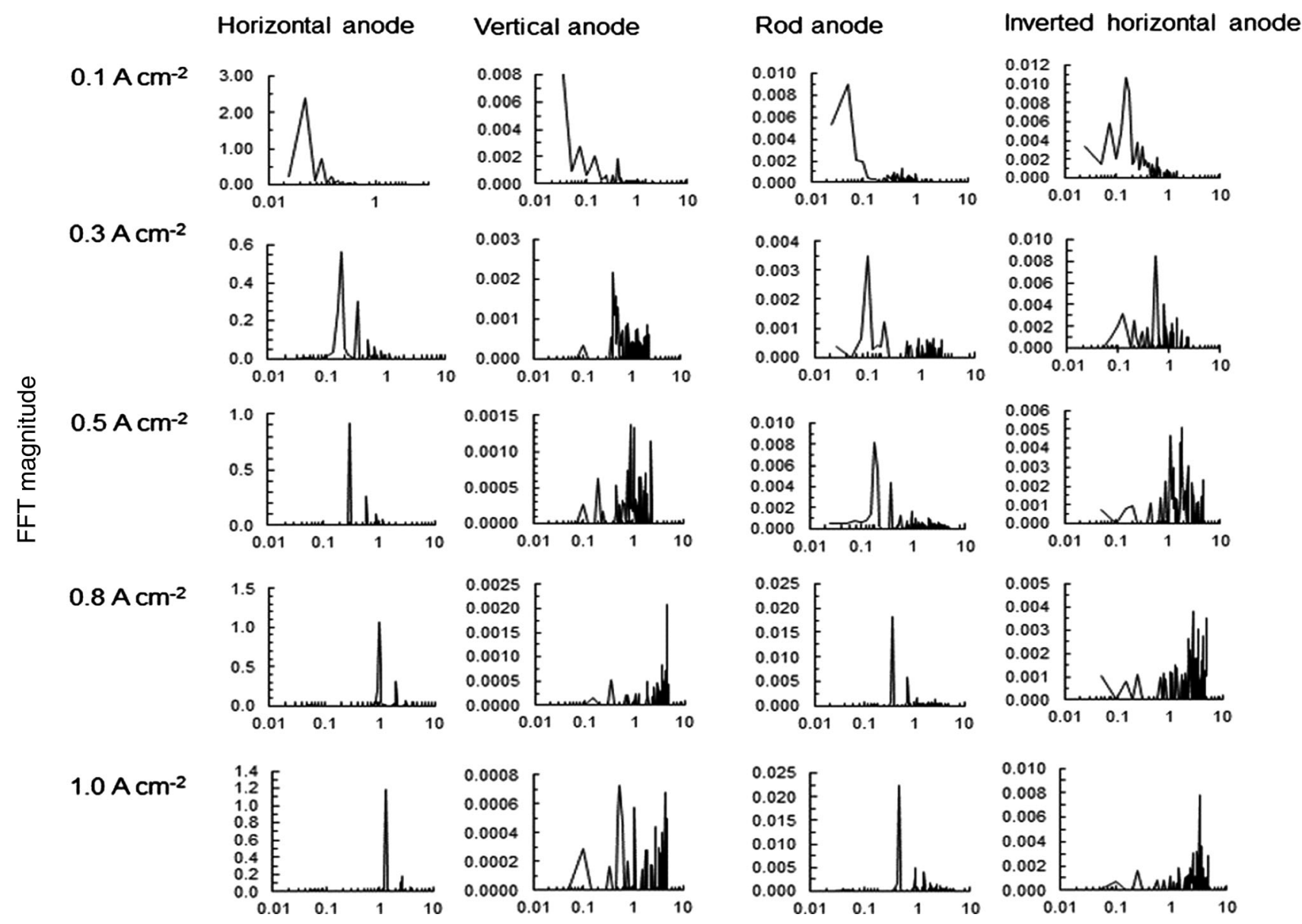

Fig. 8-FFT spectra of the potential oscillations for rod, horizontal, vertical and inverted horizontal anode for different current densities.

Table I. Bubble Detachment Time and Dominant Frequency for the Rod and the Horizontal Anode

\begin{tabular}{|c|c|c|c|c|c|c|c|}
\hline \multicolumn{4}{|l|}{ Rod Anode } & \multicolumn{4}{|c|}{ Horizontal Anode } \\
\hline $\begin{array}{l}\text { Current } \\
\text { Density, A } \\
\mathrm{cm}^{-2}\end{array}$ & $\begin{array}{c}\text { Bubble } \\
\text { Detachment } \\
\text { Time, s }\end{array}$ & $\begin{array}{l}\text { Expected Frequency } \\
\text { Based on the Bubble } \\
\text { Detachment Time, Hz }\end{array}$ & $\begin{array}{l}\text { Dominant } \\
\text { Frequency, } \\
\text { Hz }\end{array}$ & $\begin{array}{l}\text { Current } \\
\text { Density, } \\
\text { A cm }^{-2}\end{array}$ & $\begin{array}{l}\text { Bubble } \\
\text { Detachment } \\
\text { Time, s }\end{array}$ & $\begin{array}{l}\text { Expected Frequency } \\
\text { Based on the Bubble } \\
\text { Detachment Time, Hz }\end{array}$ & $\begin{array}{l}\text { Dominant } \\
\text { Frequency, } \\
\mathrm{Hz}\end{array}$ \\
\hline 0.1 & 20 & 0.05 & 0.05 & 0.1 & 20 & 0.05 & 0.05 \\
\hline 0.3 & 9.4 & 0.11 & 0.10 & 0.3 & 6.2 & 0.16 & 0.17 \\
\hline 0.5 & 5.4 & 0.18 & 0.17 & 0.5 & 3.4 & 0.29 & 0.3 \\
\hline 0.8 & 2.7 & 0.37 & 0.37 & 0.8 & 1.9 & 0.53 & 1.00 \\
\hline 1.0 & 2.3 & 0.44 & 0.45 & 1.0 & 1.5 & 0.67 & 1.29 \\
\hline
\end{tabular}

existence of many bubbles of different size, the growth and coalescence of bubbles or moving bubbles and their interaction on the surface. ${ }^{[12,26]}$ There is a lack of periodicity in the bubble noise signal and bubbles are probably detaching randomly from these surfaces in comparison with the rod and the horizontal anode.

In a laboratory cell where only a few bubbles can exist simultaneously, the high frequency and the low amplitude in potential oscillations are associated with the nucleation of the individual bubbles, while the lower frequency and high amplitude are caused by detachment of the big, coalesced bubbles. This was also reported by
Kiss et al. ${ }^{[26]}$ In Figure 8 it can be observed that, the dominant peak for the horizontal anode occurs at lower frequency, $<\sim 1.0 \mathrm{~Hz}$, while some relative larger peak(s) for vertical and inverted horizontal anode occurs at higher frequency, $>1 \mathrm{~Hz}$. It can also be seen that the vertical and the inverted horizontal anode in general give broader distribution of frequencies and lower amplitude meaning that smaller individual bubbles are released from the surface in comparison with the horizontal anode. Einarsrud et al. ${ }^{[25]}$ also found that higher frequencies are related to smaller amplitudes in potential oscillation in a laboratory cell. 
Horizontal anode

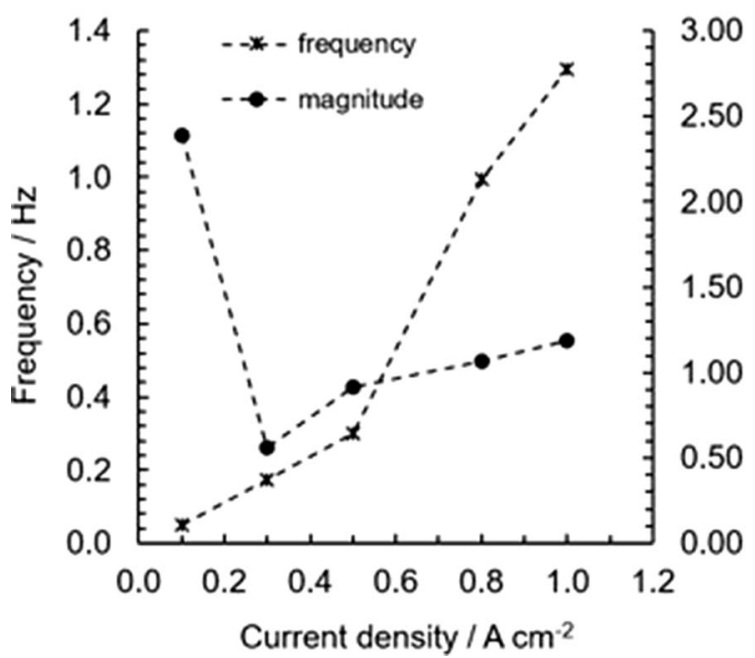

Rod anode

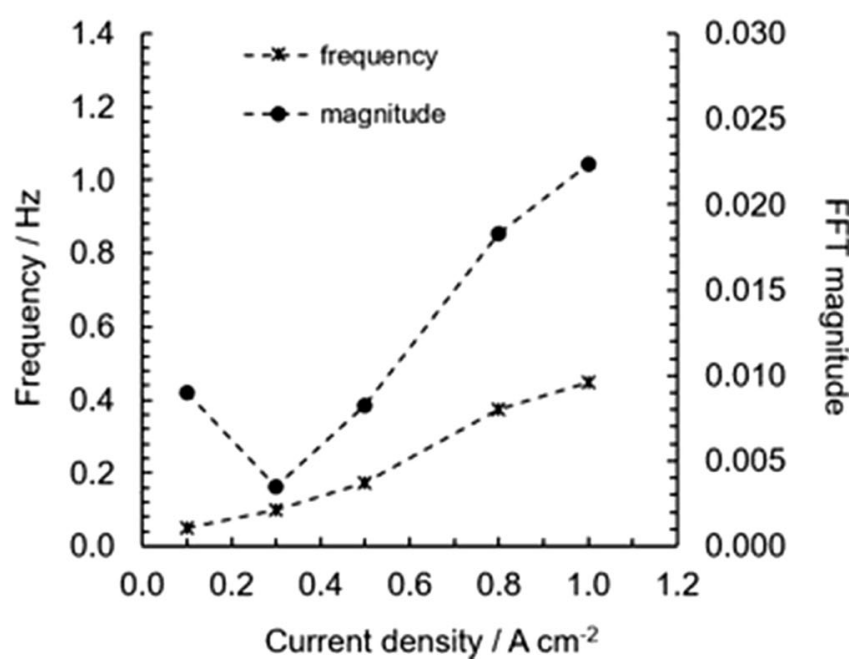

Fig. 9-Dominant frequency and amplitude for the horizontal and the rod anode at different current densities: $0.1,0.3,0.5,0.8$, and $1.0 \mathrm{~A} \mathrm{~cm}^{-2}$.

Figure 9 represents dominant frequency and amplitude for different current densities for the horizontal and the rod anode based on the FFT spectrum. The frequency and the amplitude of the potential oscillation are correlated with the nucleation, coalescence, growth and detachment of the bubbles. In general, both increased with increasing current density. Cooksey et al. ${ }^{[27]}$ observed that this effect changed with increasing current density during experiment, i.e., frequency became more dependent on current density and amplitude became less dependent. No explanation for this change was suggested. In Figure 9, it can be observed that the dominant frequency increases with the increasing current density for both anodes, likely owning to bubbles being smaller at the time of detachment. The FFT magnitude for the horizontal and the rod anode decreases going from 0.1 to $0.3 \mathrm{~A} \mathrm{~cm}^{-2}$, and after $0.3 \mathrm{~A}$ $\mathrm{cm}^{-2}$ slightly increases with the increasing current density. High value of the FFT magnitude at low current density can be explained by the large bubble retention time during which bubbles have enough time to coalesce and grow large. The long bubble retention time is also a result of a small bubble driven convection and not only low current density. With increasing current density, the bubble formation rate increases and consequently the bubble driven convection is enhanced. The FFT magnitude of the rod anode is significantly smaller than compared to the horizontal anode. This is due to the major fraction of the total current taken up by the vertical surface with the formation of smaller bubbles as discussed in relation to Figures 3 and 4.

\section{CONCLUSION}

From the polarization curves of the four anode designs (horizontal, vertical, rod and inverted horizontal), the vertical anode and the inverted horizontal operated at lowest potentials. Above $1 \mathrm{~A} \mathrm{~cm}^{-2}$, the vertical anode showed the lowest potential, a result related to an easier bubble release from the vertical anode arising from a more effective bubble-induced convection. As the current increases, the transition towards smaller noise is pronounced for the horizontal anode and to some degree for the vertical anode and inverted horizontal anode. This transition is caused by increased bubble-induced convection effectively removing the bubbles, the effect being relatively largest for the horizontal anode with a large increase in current, 0.5 to $1.5 \mathrm{~A} \mathrm{~cm}^{-2}$, going from 2.1 to $2.3 \mathrm{~V}$, respectively. The improved performance of the horizontal anode in this current density range can be important considering current increase in industrial cells which today operate at approx. $0.9 \mathrm{~A} \mathrm{~cm}^{-2}$, although the dimensions and geometry of the laboratory and industrial scale anodes are not directly comparable. FFT analysis of the chronopotentiometric data gave a dominant frequency only for the horizontal anode and the rod anode. The absence of a dominant frequency for the vertical and inverted horizontal anode indicates random bubble noise caused by effective bubble release. The bubble release time corresponded well with the dominant frequency for the rod anode for all current densities and for the horizontal anode at lower current densities.

\section{ACKNOWLEDGMENTS}

Open Access funding provided by NTNU Norwegian University of Science and Technology (incl St. Olavs Hospital - Trondheim University Hospital).

\section{OPEN ACCESS}

This article is licensed under a Creative Commons Attribution 4.0 International License, which permits use, sharing, adaptation, distribution and reproduction 
in any medium or format, as long as you give appropriate credit to the original author(s) and the source, provide a link to the Creative Commons licence, and indicate if changes were made. The images or other third party material in this article are included in the article's Creative Commons licence, unless indicated otherwise in a credit line to the material. If material is not included in the article's Creative Commons licence and your intended use is not permitted by statutory regulation or exceeds the permitted use, you will need to obtain permission directly from the copyright holder. To view a copy of this licence, visit http://creativec ommons.org/licenses/by/4.0/.

\section{REFERENCES}

1. V. Lacassagne, C. Bessada, P. Florian, S. Bouvet, B. Ollivier, J.-P. Coutures, and D. Massiot: J. Phys. Chem. B, 2002, vol. 106 (8), p. 1862.

2. Thonstad, J., P. Fellner, G.M. Haarberg, J. Híveš, H. Kvande, and $\AA$. Sterten: Aluminium electrolysis : fundamentals of the HallHéroult process. 3rd ed. 2001, Düsseldorf: Aluminium-Verlag, p. $70-86$.

3. J. Thonstad: J. Electrochem. Soc., 1965, vol. 111 (8), pp. 959-65.

4. Picard, G.S., E.C. Prat, Y.J. Bertaud, and M.J. Leroy, in Light metals 1987 ed. R.D. Zabreznik,(Warrendale: Metallurgical Society, 1987), p. 507-17.

5. A. Kisza, J. Thonstad, and T. Eidet: J. Electrochem. Soc., 1996, vol. 143 (6), pp. 1840-47.

6. Grjotheim, K. and H. Kvande: Introduction to aluminium electrolysis : understanding the Hall-Héroult process. 2nd ed. 1993, Düsseldorf: Aluminium-Verlag, p. 147-58.

7. J. Thonstad: J. Electrochem. Soc., 1965, vol. 111 (8), pp. 955-959.

8. Fortin, S., M. Gerhardt, and A.J. Gesing, in Light metals 1984, ed. J.P. McGeer,(Warrendale: Metallurgical Society of AIME, 1984), p. $721-41$.

9. Zhao, Z., Z. Wang, B. Gao, Y. Feng, Z. Shi, and X. Hu, in Light Metals 2015, ed. M. Hyland,(Cham: Springer, 2015), p. 801-06.
10. L. Cassayre, T. Utigard, and S. Bouvet: JOM, 2002, vol. 54 (5), pp. $41-45$.

11. Einarsrud, K.E., S.T. Johansen, and I. Eick, in Light Metals 2012, ed. C.E. Suarez,(Hoboken, NJ: Wiley, 2012), p. 875-80.

12. R.J. Thorne, C. Sommerseth, A.P. Ratvik, S. Rorvik, E. Sandnes, L.P. Lossius, H. Linga, and A. Svensson: J. Electrochem. Soc., 2015, vol. 162 (8), pp. E104-14.

13. Thorne, R.J., C. Sommerseth, A.M. Svensson, E. Sandnes, L.P. Lossius, H. Linga, and A.P. Ratvik, in Light Metals 2014, ed. J. Grandfield,(Hoboken, NJ: Wiley, 2014), p. 1213-17.

14. Thorne, R.J., C. Sommerseth, E. Sandnes, O. Kjos, T.A. Aarhaug, L.P. Lossius, H. Linga, and A.P. Ratvik, in Light Metals 2013, ed. B. Sadler,(Springer, 2013), p. 1207-11.

15. R.J. Thorne, C. Sommerseth, A.P. Ratvik, S. Rorvik, E. Sandnes, L. Lossius, H. Linga, and A. Svensson: J. Electrochem. Soc., 2015, vol. 162 (12), pp. E296-E306.

16. Kjos, O.S., T.A. Aarhaug, E. Skybakmoen, A. Solheim, and H. Gudbrandsen, in 10th Australasian Aluminium Smelting Technology Conference, 2011. Launceston, Tasmania.

17. Eidsvaag, I.A., E. Sandnes, and H. Åsheim. 2016, NTNU.

18. J. Thonstad: Electrochim. Acta, 1967, vol. 12 (9), pp. 1219-26.

19. K.E. Einarsrud and S.T. Johansen: Prog. Comput. Fluid Dyn., 2012, vol. 12 (2-3), pp. 119-30.

20. K. Zhang, Y. Feng, P. Witt, W. Yang, M. Cooksey, Z. Wang, and M. Schwarz: J. Appl. Electrochem., 2014, vol. 44 (10), pp. 1081-92.

21. Xue, J. and H.A. Øye, in Light Metals 1995, ed. J. Evans,(Warrendale: TMS, 1995), p. 265-71.

22. Cassayre, L., G. Plascencia, T. Marin, S. Fan, and T. Utigard, in Light Metals 2006, ed. T.J. Galloway,(Warrendale: TMS, 2006), p. 379-83.

23. Z. Zhao, Z. Wang, B. Gao, Y. Feng, Z. Shi, and X. Hu: Metall. Mater. Trans. B, 2016, vol. 47 (3), pp. 1962-75.

24. Z. Zhang, J.M. Werner, and M.L. Free: J. Electrochem. Soc., 2018, vol. 165 (15), pp. J3246-52.

25. Einarsrud, K.E. and E. Sandnes, in Light Metals 2011, ed. S.J. Lindsay,(Springer, 2011), p. 555-60.

26. Kiss, L.I. and S. Poncsak, in Light metals 2002, ed. W.A. Schneider,(Warrendale: TMS, 2002), p. 217-23.

27. M. Cooksey, M. Taylor, and J. Chen: JOM (TMS), 2008, vol. 60 (2), pp. 51-57.

Publisher's Note Springer Nature remains neutral with regard to jurisdictional claims in published maps and institutional affiliations. 